$\xi=$

\title{
The development of a guide for nurse leaders in higher education
}

\author{
Danita R. Potter, PhD ${ }^{1 *}$, Danita Tolson, EdD ${ }^{2}$ \\ ${ }^{1}$ Director \& Associate Professor, RN-BSN Program, Northwestern State University, College of Nursing, Shreveport, LA \\ ${ }^{2}$ Assistant Professor \& Chairperson, Baccalaureate Nursing Education, Coppin State University, Baltimore, MA. \\ *Corresponding author E-mail: potterd@nsula.edu
}

\begin{abstract}
Aim: Little is known regarding mentoring and supportive resources to assist, retain, and support nurse administrators at Historically Black Colleges and Universities (HBCUs). The purpose of this paper is to discuss and describe the analysis of nurse leaders expressed journey to leadership, and a provide a guide for nursing leadership development.

Methods: Thematic analysis of nurse leaders expressed challenges and terms and concepts of nursing leadership that prepared them for their role as a successful nurse leader.

Results: Themes were derived from the analysis of past distinguished nurse leaders and provided a foundation for the development of mentoring guide for African American nurse leaders.

Conclusions: Mentoring and supportive resources are essential in retaining nurse leaders in higher education. A guide on how to retain and support nurse administrators at HBCUs. This guide serves as a foundation for colleges and universities in their recruitment, orientation, and retention of nurse administrators in higher education.
\end{abstract}

Keywords: Leaders; Higher Education; Mentoring; Models.

\section{Introduction}

Little is known regarding mentoring and support resources for Nurse Leaders and its impact on retention of leaders at Historically Black Colleges and Universities (HBCUs). Little research addresses the experiences of Black or ethnic minority nurses (Smith, 2005) and its impact on nurse leadership or faculty shortage at HBCUs.

Mentoring can facilitate needed support to new and incumbent administrators. Major institutions have a track record for integration of mentoring at the programmatic level and abroad. Mentoring is usually addressed for faculty and deans and little discussed for midlevel administrators, yet critical for their growth and success.

It was essential to look for the service of African-American Leaders in Nursing. African American Nurse Leaders are in great demand in leadership roles in practice, education, and research. Today, there are over 2 million nurses in the United States, and only $12 \%$ are from ethnic or racial minority groups. According to American Association of Colleges of Nursing (AACN, 2011), the Institute of Medicine (IOM) recommends that by year 2020 eighty percent of nurses will have a minimum of bachelor's degree in nursing. There continues to be a very high demand for administrators and executives, particularly African American nurse administrators at HBCUS. AACN proposed four primary areas in its strategic plan and the IOM Report. These included developing leaders over the future of nursing, advancing the educational preparation of nursing workforce at the baccalaureate, master's and doctorate levels. Leveraging the academic-practice interface to drive change, and to provide leadership to facilitate inter-professional education.

\section{Methods}

\subsection{Data Analysis}

A qualitative analysis approach was used was used to analyze statements of nurse leaders within Dr. Hattie Bessent's (2005) book. See Table 1.1 Using a qualitative analysis approach, eleven nurse leaders of the project. This qualitative analysis uses line-by-line coding to determine themes. The nurse leaders' statements/stories on leadership were described verbatim individual responses were clustered for commonalities on leadership and used to draw themes.

Thematic analysis was used to analyze the expressed concepts and terms of eleven nurse leaders described throughout the book. Thematic analysis is a qualitative analysis using line-by-line coding to determine themes. As outlined by Braun and Clarke (2006), all statements are independently examined and coded by two individuals. The individuals then meet to reexamine the codes and create themes. This examination continues with reexamination for any discrepancies in their analysis until $100 \%$ agreement has been achieved. Charts and tables were created, which included name of themes, number of individuals, percentages, and number of themes for the categories. An analysis of the data for miscoding and other possible statistical concerns was performed.

Figure 1.1 shows the distribution of nurse leaders expressed concepts and terms. Seven categories included 1) Education/Preparedness $(n=10,22 \%) ; 2)$ People Dynamics $(n=9,20 \%) ; 3)$ Communication $(\mathrm{n}=8,18 \%)$; 4) Decision making $(\mathrm{n}=7,15 \%)$; 5) Commitment $(\mathrm{n}=5,11 \%) ; 6)$ Mentoring $(\mathrm{n}=3,7 \%)$; and 7$)$ Vision $(\mathrm{n}=3,7 \%)$. 
Concepts and terms of challenges/barriers expressed by nurse leaders (See Figure 2.1) revealed a total of four categories/themes which were 1) Work/Environment Challenges ( $n=14,38 \%)$; Racism/Sexism/Criticism Challenges $(\mathrm{n}=14,38 \%) ; 3)$ Politics $(\mathrm{n}=8,21 \%)$; and 4) Financial/Funding Pressures $(n=1,3 \%)$.

Table 1.1 displays seven themes of expressed perspectives of nurse leaders in Dr. Bessent's Book titled, The Soul of Leadership: Journeys in leadership and Achievement with distinguished African American Nurses. This table displays the theme categories, percentage of leader expressions, and a sample of verbatim expression (s).
The most common theme was education, and a sample expression of education was "life-long to education" and "study leadership." People dynamics was another theme, and a sample expression was "Understand group dynamics, organizational behaviors, and interpersonal analysis." The next five themes and sample expressions are displayed in Table 1.1 below. The seven themes were used to develop mentoring guide.

Table 1: Leadership Expressed by Nurse Leaders: Themes, Percentages, \& Verbatim Expressions

\begin{tabular}{lll}
\hline Name of Theme/ Number of Thematic Examples of Verbatim Category Expressions (\%)expressions \\
\hline & & \\
Education & $22 \%$ & "life-long commitment to education"; "study leadership"; "remain a student" \\
People Dynamics & $20 \%$ & "understand group/organizational dynamics"; "improve environment not people" \\
Communication & $18 \%$ & "have good manners" "choice of words" \\
Decision making & $15 \%$ & "learn how to delegate...do it purpose and respect"; "confront issues"; "take risks" \\
Commitment & $11 \%$ & "except full responsibility"; "when facing a facing a storm, use calm resolve" \\
Mentoring & $7 \%$ & "we have to mentor each other"; "mentor to complete the doctorate" \\
Vision & $7 \%$ & "have vision"; "good leaders are reflective" \\
\hline
\end{tabular}

Nursing leadership was explored by looking closely at the essential terms and concepts used by the leaders in Dr. Bessent's book. Figure 1.1 displays a distribution of concepts and terms used in nursing leadership throughout the journey of African American nurse leaders. The terms consisted of education, people dynamics, communication, decision- making, commitment, mentoring, and vision.

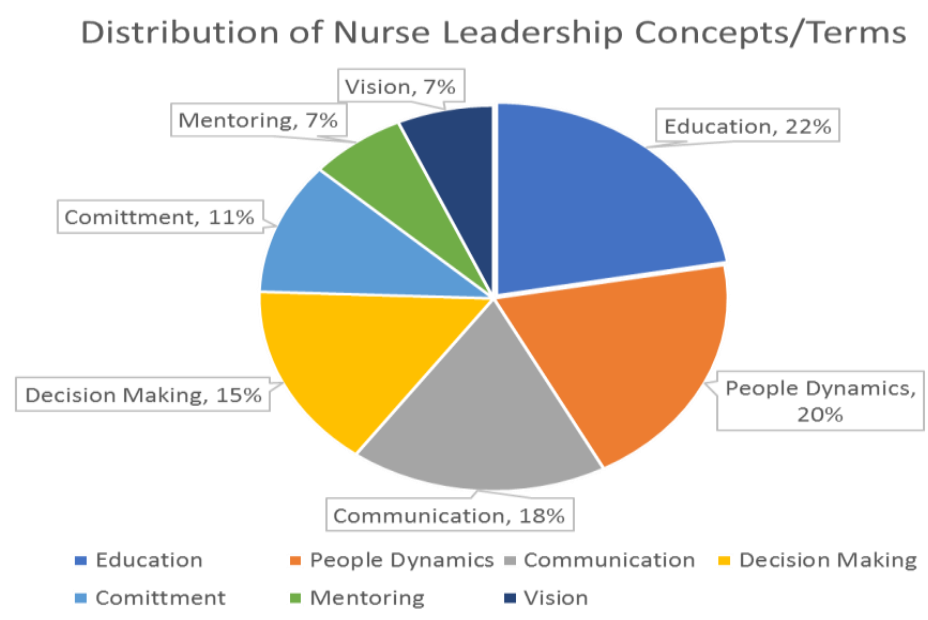

Fig. 1.1: Nurse Leadership Concepts/Terms.

Nurse leaders also expressed challenges that they endured during their journey. Figure 2.1 displays themes derived from expressed challenges including the categories and percentages. There were four categories/themes of expressed challenges which were categorized as workplace $(38 \%)$, racial/gender (38\%), political $(21 \%)$, and financial $(3 \%)$ challenges.

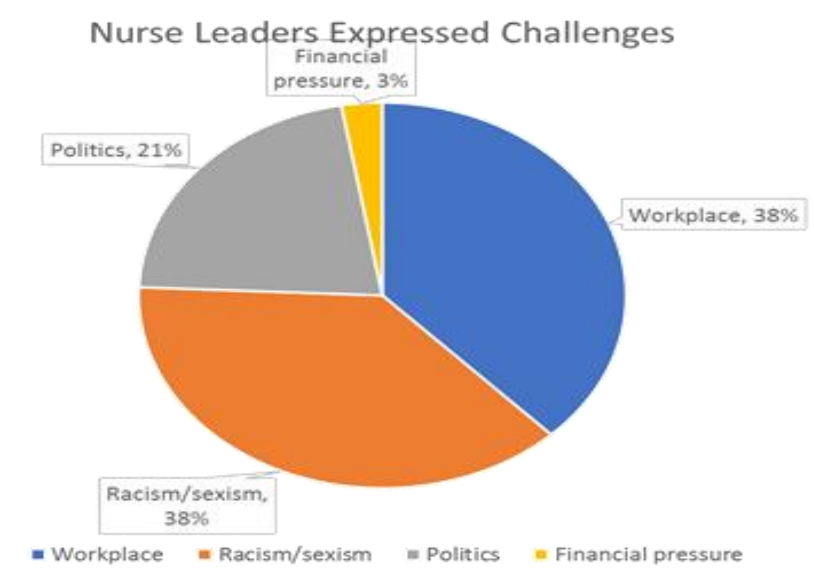

Fig. 2.1: Themes Derived from Nurse Leaders Expressed Challenges.

\section{Summary}

Mentoring should be a mutual agreement between the mentor and mentee. Oladipo, Adebakin, and Iranloye (2016) define mentorship as a relationship between the mentor, who is more experienced and knowledgeable, and the mentee, who is the learner, that develops skills and knowledge from the mentor. Casey and Clark (2011) defines a mentor as one who is wiser and more experienced who coaches, supports, guides, and encourages the mentee in their learn- 
ing process. An effective nursing leader who mentor is an individual who has an interest in the mentee's positive career development. Therefore, the recommended nursing leader qualities that should be possessed are education, knowledgeable about the position, task or skill, risk-taker, a visionary, approachable, experienced, organized, confident, good collaborator, honest, genuine, effective communicator, motivator, encourager, coach, good role model, empowering, and mentor (Rath \& Conchie, 2008). The mentee qualities are flexibility, accepting feedback, respectful, dedication, humble but aggressive, and willingness to follow through the mentorship process. In order to progress and be successful in the leadership mentormentee relationship, both the mentee and mentor have to have the willingness and share similar objectives and goals.

The mentor-mentorship process is essential to produce potential nursing leaders at HBCUs; therefore, if the nursing mentor in an administrative position does not possess the willingness or common goals then the mentorship process will be broken and ineffective. The purpose of the mentorship process is to assist with shaping the mentor's development in a leadership position, as well as assisting with the administrator's succession plan at a HBCU to shape the mentee into a leadership position to perform effectively and efficiently (Potter \& Tolson, 2014; Rath \& Conchie, 2008).

Potter and Tolson's (2014) Mentoring Guide for faculty consisted of four core concepts: 1) mentor, 2) mentoring program, 3) mentee and 4) supportive systems. The newly developed guide for nurse administrators includes concepts/terms analyzed into themes of success for nurse leaders (see Figure 3.1). Part I consists of education, people dynamics, communication, decision making, commitment, mentoring, and vision. Part II of the guide consists of understanding barriers or challenges to success.

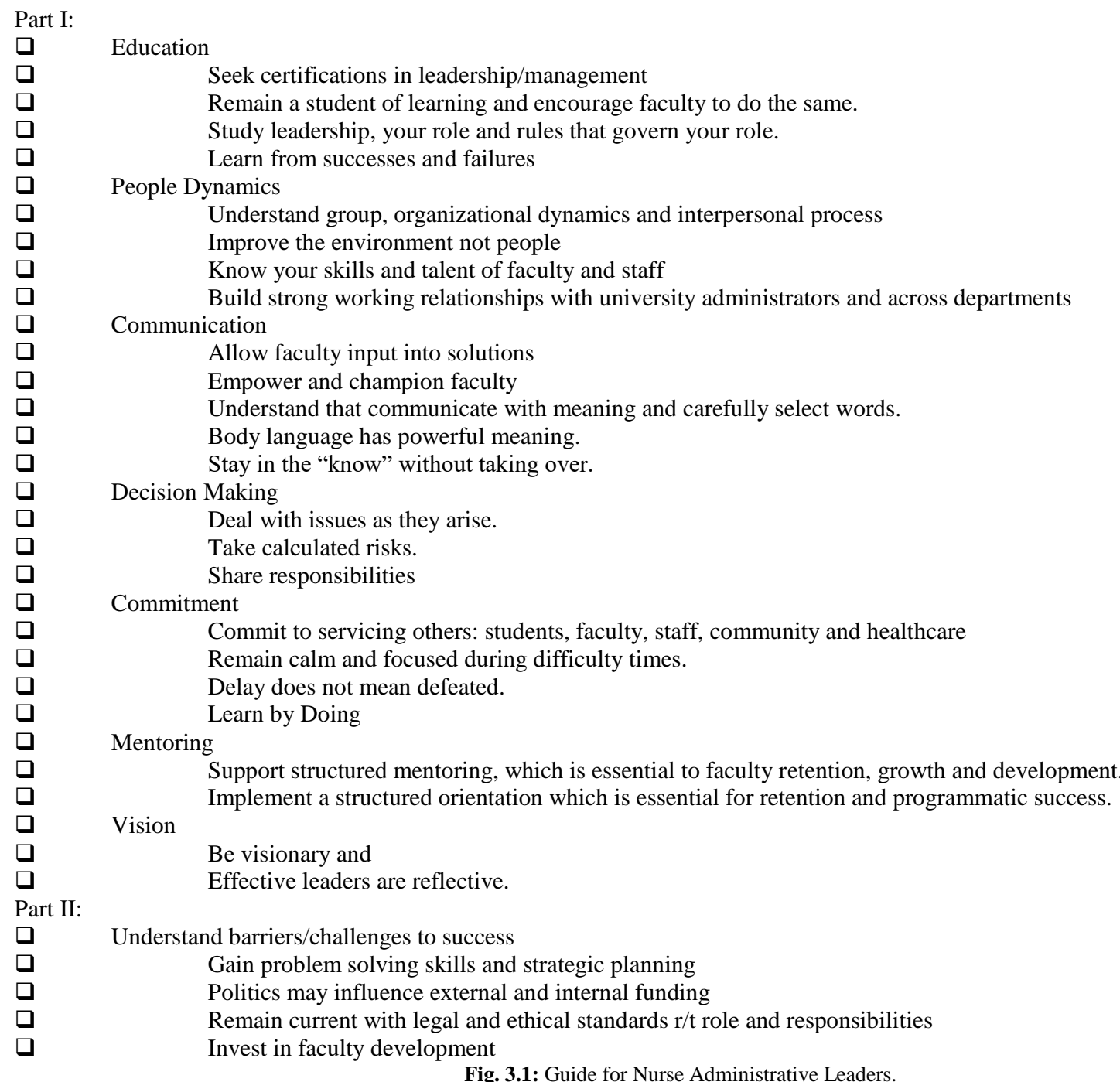

The Nurse Administrator Guide was developed using a positive mentor-mentorship process developed to also assist with decreasing the nursing shortage as well as producing additional nursing mentors. Integration of themes derived from distinguished nurse leaders was included in the newly developed guide (Figure 3.1).

\section{Conclusion}

Lack of research exists on mentoring minority nurse leaders into roles of nursing administration or faculty roles at HBCUs. The literature provided articles on mentor and mentees but did not focus on nursing, leadership positions, or minorities. The Guide for Nurse Administrative Leaders (figure 3.1) was developed based on past distinguished nurse leaders from Dr. Bessent's book and the author's experience. The literature also provided limited articles on mentoring women and suggested that men had an easier time finding a mentor even when the majority of the nursing workforce is populated with women (Sandberg, 2014). Additional research is needed to support minority nurses who desire to excel in administrative positions. The Guide for Leadership is not limited to minority nurses desiring to be a leader, thus may be implemented in various disciplines and areas. The leadership guide was developed as beginning model to be further expanded with theory and to assist with succession planning, mentoring, and decrease the nursing leader shortage. 


\section{References}

[1] AACN (2011). Strategic Planning \& IOM Report. file:///C:/Users/DANITA 1/AppData/Local/Temp/IOMStrategicPlanning.pdf

[2] Bessent, H. (2005). The soul of leadership: Journeys in leadership and achievement with distinguished African American nurses. New York: NLN

[3] Braun, V., \& Clarke, V. (2006). Using thematic analysis in psychology. Qualitative Research in Psychology, 3, 77-101. https://doi.org/10.1191/1478088706qp063oa.

[4] Casey, D. C. \& Clark, L. (2011). Roles and responsibility of the student nurse mentor: an update. British Journal of Nursing, 20(5), $933-$ 937. Retrieved from EBSCOhost database https://doi.org/10.12968/bjon.2011.20.15.933.

[5] Oladipo, S., Adebakin, A. B., \& Iranloye, O. F. (2016) Mentoring and succession of administrators: Critical issues in public and private secondary schools in Lagos State, Nigeria. Bulgarian Journal of Science and Education Policy, 10(1), 19-38. Retrieved from EBSCOhost database.

[6] Potter, D. R., \& Tolson, D. (2014). A mentoring guide for nursing faculty in higher education. International Journal of Caring Sciences, 7(3), 727-732.

[7] Rath, T., \& Conchie, B. (2008). StrengthsFinders 2.0: Strengths based leadership: Great leaders, Teams, and why people follow. New York, NY: Gallup Press.

[8] Sandberg, S. (2014). Lean In: Women, Work, and the Will to Lead. NY: Random House. 